\title{
On Chinese City of Roof Garden Landscape Design of the Plant Allocation Principle and Method
}

\author{
Zhimin Yao \\ Zhengzhou Normal University, Zhengzhou, China \\ yaozzsf@163.com
}

Keywords: Roof garden, Plant, Landscape design

Abstract. In this paper, the existence of our country city of Roof garden landscape design problems are discussed through the analysis of plant, configuration principle in designing Roof garden, expounds the Countermeasures of plant configuration of modern city landscape design of the Roof garden, has the instruction significance to the city living environment construction of good.

Building roof space has unique environmental features, which determines the Roof garden plant must have a happy light, heat resistance, cold resistance, wind proof, dust-proof, anti pollution, is not strict, strong vitality, positive, slow growth, good maintenance, shallow root or root system developed features of the soil requirements.

\section{Introduction}

The modern city of Roof garden landscape design is not limited to simple "green roof" and "construction technology". It is a part of the modern city landscape ecological design, ecological building roof space is city design and city offbeat open space design content.

\section{Plant Allocation Principle of Roof Garden in Landscape Design}

Adaptability principle, this is city plant survival condition. Study a proof, garden trees of secular growth affected by environmental factors, to make the garden plant configuration is relatively stable, we must first consider the plant's survival condition, also known as ecological factors, the lack of which plants cannot survive. Professor Chen Youmin by means of modern science and technology on the comprehensive analysis on the basis of all kinds of natural factors, divided our country into the cold temperate zone, temperate zone, North warm temperate, warm temperate, warm temperate, subtropical, south subtropical, tropical and south subtropical, Qinghai Tibet Plateau climate green area ten big and 20 small climate dis trict, and details of each climatic region suitable plants.

Effect of adaptability principle of a plant species differences. Adaptability refers to in the same climate Green Zone, in different geographical position, i.e. different city because of the difference of natural geography, topography, soil, hydrological and geological conditions, the plant species had different. As the North China Plain belongs to the warm temperate zone of Beijing is located in the fertile, Roof garden can be used for many plant species, and the victory of Shandong Dongying oilfield is located in the eastern coastal area, for saline alkali soil, see Gui Xiangliu (Sha Zao), Yucca gloriosa, purple small chestnut and white clover and other rare plant species. Dalian city for soil thin, little rain, the city landscaping for turf and ground cover, shrubs and less, so the roof greening in general also with lawn or artificial turf as a multi .

The principle of appropriateness decision plant survival in the Roof garden. In the same city, city center district environment and the outskirts of the natural environment is not exactly the same, and the small environment and ground environment building roof is different, so there are some adaptability suitable plant cannot survive in Roof garden, and some exotic species and can grow in the roof space. As mentioned before, the Roof garden plant requires appropriate principle of special, such as in Guangxi, Nanning, banyan tree and palm plants is the most important, the most widely used of the city landscape plants, they have good shade, landscaping, landscaping features, but 
because of the banyan tree developed root system, palm plants on soil conditions certain requirements, so it is rarely used for roof greening.

Applicability of the principle -- to create different nature, function, style of Roof garden landscape conditions. Different function, purpose, nature, size, style, form of the Roof garden on the selection of plants have different requirements, it also depends on the interpretation and understanding of plant functional designers use.

\section{Different Types of Roof Garden Plant Selection}

Leisure Roof garden, plant is an important element of the landscape. Family Roof garden provides different uses for the owners, such as shade, catering, entertainment, talk, walk, see. Among them, along the wall and fence planting climbing plants, potted plant, fine layout flowering shrubs and movable plant box. And enterprise units, residential or internal open hotel podium of the Roof garden, the area is larger, its function in addition to landscaping, greening the environment, but also master degree thesis design thinking of modern city of Roof garden landscape is people outdoor leisure entertainment space, landscape elements are complex, the use of plant landscape is very important. A variety of planting area of shrubs, flowers, by choice and rockery stone, road, square, reasonable layout view, barrier, color matching, style shape are required to choose suitable plants to meet, such as Hunan Caixin International Hotel multiple theme sky gardens belong to this nature.

The profitability of Roof garden is mainly to provide the nightlife place is restricted, open public recreation entertainment. It requires hard certain space, attractions, sketch, flowers and other requirements of exquisite, the aim is to create an active atmosphere. Plant configuration to consider the use of objective requirements, choose more colorful, the four seasons normally open, no pollution of aromatic varieties.

Research teaching or to green for the purpose of the roof garden, orchard, nursery and roof greening, has a special selection, roof greening can use artificial turf and inexpensive maintenance by lawn planting.

\section{To Create Different Styles According to the Different Functions of the Building Roof Plant Landscape}

Rule based Roof garden multiple choice cut resistant shrubs. Free style warm and lively garden, then choose more tree branches attitude and handsome, peculiar shape, color of the shrubs and flowers. The use of plant configuration of color can create a different style gardens, such as red maple, red leaf plum, red wooden, pomegranate, peach, rose, rose, camellia and so on in order to give people a warm atmosphere, exciting effect, and the use of green plants such as boxwood, Ligustrum lucidum, palm, Pistacia chinensis Bunge, bamboo etc. can create a quiet and pleasant, harmonious atmosphere.

In the factory district, according to its production and pollution characteristics, targeted selection of anti pollution plant in order to improve the roof, Protect environment aim. In order to cope with the sulfur dioxide, tree species in the Yangtze River downstream area with strong resistance, wide YuLan have oleander, Ligustrum lucidum, camphor, Distylium racemosum, coral tree, bone structure, camellia, ten credit, holly, palm, laurel, yucca, guava, citrus, acacia, Chinese tallow tree, Chinese rose. In the photochemical pollution, strong resistance species are silver disappeared, Japanese black pine, Cinnamomum camphora, Pittosporum tobira, oleander, Japanese privet, holly, big flower gardenia, large Hydrangea etc.. The chlorine and hydrogen chloride resistant strong species are Acacia, wood, Bauhinia, wisteria, Huai etc..

Hospital and Sanatorium can go to create the existing landscaping and environmental protection, health care, for the use of plant color, and adjust the mentality of people's ecological Diao, garden.

Roof garden landscape plants configuration should follow the diversity and symbiosis, adaptability, art of scientific principles, should be carefully chosen with shrubs, flowers and lawns are good ornamental and climbing plants for landscaping. Differences in natural geographical and climatic conditions also controls Roof garden shrubs, lawns, flowers and plants disposition 
proportion, such as the northern winter cold for a long time, little rain, there is often a sand storm, soil thin and poor, the growing season is short, only with artificial turf and vegetable planting box this way only for maintenance management. The Yangtze River Basin, Jiangsu and Zhejiang, Hunan, Jiangxi, Hubei several Province, four distinct seasons, abundant rainfall, plant variety, growth period is long, with shrubs, flowers, by natural cultivation oriented, moderate with potted plants, tree box. The coastal area of typhoon, monsoon, strong sunlight, multi-purpose evergreen small shrubs wall and shade. Guangxi, Guangdong and other cities with a tropical monsoon climate characteristics, high temperature and rainy in summer half year for the wet season, the winter half year is warm and drought in dry season. Summer rainy and typhoon, strong sunlight, Roof garden in the shade as the main purpose, always use the local grapes, triangle plum, gold melon scaffolding, and cooperate with Joe shrubs, flowers, can not only shade, and economic value.

\section{The Environmental Characteristics and the Roof Planting Roof Space Countermeasures}

Because the roof space environment from the earth, and the soil, surface water system without direct contact, also cannot obtain the groundwater recharge, the lack of regulation of microbial nature normal water and nutrient in soil and plant planting soil thickness, load limit, light, wind speed, moisture evaporation and humidity quickly fast changes in environmental characteristics in a certain restricted roof for the growth and development of plants, but the city of high-altitude air unobstructed, reduce pollution, air turbidity is relatively low, the solar radiation is strong, but also provides the conditions for plant photosynthesis, is conducive to the growth of plants. In view of the above characteristics, the Roof garden plant planting design should take the necessary countermeasures.

The widespread construction of Roof garden, will be able to generate the following utility:

Reduce the heat is land effect, prevent excessive drying, improving city microclimate.

Through the soil adsorption, absorption by plants, microbial decomposition and other effects, purify the atmosphere of the city.

Due to the buffering effect of storage roots, vegetation water interception, alleviate the stormwater drain.

\section{Conclusion}

Roof garden landscape design as a modern man against the current deteriorating urban environment, with "visual aesthetic" meaning, "landscape habitat" and "system" meaning. It is the modern science and technology, art and human culture ideal vector. As the physical sense of the landscape, it is in the construction process of modern city living environment has profound significance. The use of artificial landscaping of Roof garden architectural appearance, improve the construction of the space environment is the important content of the pursuit of modern ecological architecture. The special background and foundation of roof space determines the requirements it is different with the other types of landscape design, the content and method. The common responsibility of modern city landscape design of Roof garden's landscape architect and architect, request them from design to construction each step closer cooperation.

\section{References}

[1] JERRY HARPUR,DAVID STEVENS.Roof Gardens: Balconies \&Terraces. . 2005

[2] Schiffer Books. Green Roofs: Ecological Design \& Construction. . 2005

[3] Han Lili, a single, Li Lianlong Beijing roof greening plant configuration [J]. construction technology. 2009 (13)

[4] Zhao Yuting, Hu Yonghong, Zhang Qixiang. Research progress of green roof plants selection [J]. Shandong forestry science and technology. 2004 (02) 
[5] Qu Jie, Gong Hui. The Roof garden plant selection and configuration of [J]. Shanghai commercial. $2010(01)$

[6] Yang Sen, Zhigang Zhao. Application of Landscape Ground Cover Plants in the city of Roof garden [J]. Anhui agricultural science. 2009 (06)

[7] Zhao Weiyan. In China, the status and role of the Roof garden design principles [J]. Henan agriculture. 2009 (04)

[8] Jian Shuguang, Xie Zhenhua, Zhang Qianmei, Ao Huixiu, Wei Qiang, Liu Shizhong, Ren Hai. The natural growth of Guangzhou city roof plant [J]. Chinese wild plant resources in 2004 (06). 